\title{
IMPLEMENTATION OF RESTORING EFFECTIVE SLEEP TRANQUILITY (REST) ON SLEEP QUALITY AND RESTORATION OF MOTOR ABILITY IN POST-STROKE PATIENTS
}

\author{
Hendri Kurniawan, Roh Hastuti \\ Department of Occupational Therapy, Health Polytechnics, Ministry of Health, Surakarta
}

\begin{abstract}
Background: The majority of post-stroke patients experience sleep disturbances and is thought to be the cause of fatigue, emotional, and cognitive (memory) disturbances. This situation affects the patient's participation in the rehabilitation program so that it has an impact on the process of neuronal plasticity and motor recovery. Restoring Effective Sleep Tranquility (REST) is an occupational therapy intervention program based on cognitive behavioral therapy to treat sleep disorders. The purpose of this study was to examine the effect of restoring effective sleep tranquility (REST) on sleep quality and motor skills of post-stroke patients in a neurorehabilitation program.

Subjects and Method: This was a quasi-experimental pre-test \& post-test with control design conducted at the Mandiri Center and Neurorehabilitation Clinic, Jakarta, from July to September 2019. A sample of 40 post stroke patients was selected at random and were divided into treatment groups (20 people) and control (20 people). The dependent variables were sleep quality and motor skills. The independent variable was REST. The data of sleep quality was measured by Pittsburg Sleep Quality Index (PSQI) and Modified Motor Assessment Scale (MMAS). The data were analyzed by paired t test and Mann Whitney.

Results: The majority of the samples were male (60\%), stroke onset >2 years $(52.5 \%)$, and had sleep disturbances (100\%). In the treatment group, the mean of PSQI and MMAS scores before intervention was Mean=9.55; $\mathrm{SD}=2.58$ and Mean $=7.90 ; \mathrm{SD}=$ 2.47, and that in after intervention was Mean=19.60; $\mathrm{SD}=1.03$ and Mean= 25.65; $\mathrm{SD}=$ 1.09. In the control group, the mean of PSQI and MMAS scores before intervention was Mean $=9.40 ; \mathrm{SD}=1.69$ and Mean $=8.65 ; \mathrm{SD}=1.59$, and that in after intervention was Mean $=19.95 ; \mathrm{SD}=1.20$ and Mean $=23.80, \mathrm{SD}=1.25$. Those mean differences were statistically significantly $(\mathrm{p}<0.050)$. The mean change in PSQI $(\mathrm{Mean}=0.75 ; \mathrm{SD}=0.55)$ and MMAS (Mean=6.05; $\mathrm{SD}=2.09$ ) scores in the treatment group was higher than PSQI (Mean $=0.75 ; \mathrm{SD}=0.55)$ and MMAS (Mean=3.85; $\mathrm{SD}=1.35)$ scores in the control group. The comparative test showed a significant difference $(\mathrm{p}=0.001)$ in changes in PSQI and MMAS scores between the treatment and control groups.
\end{abstract}

Conclusion. REST has a significant effect on improving sleep quality and restoring motor skills in post-stroke patients.

Keywords: stroke, restoring effective sleep tranquility, neurorehabilitation

\section{Correspondence:}

Hendri Kurniawan. Department of Occupational Therapy, Health Polytechnics, Ministry of Health Surakarta. Jl. Capt. Adisoemarmo, Karanganyar 57173, Central Java. Email: kurnia_hyckle@yahoo.co.id. Mobile: +628156753959. 